\title{
From Exploitation to Exploration: A Staged Model of Supplier Information Technology Use for Buyer Value Creation
}

\author{
Dr. David S. Preston \\ Neeley School of Business \\ Texas Christian University \\ d.preston@tcu.edu
}

\author{
Dr. Daniel Q. Chen \\ Neeley School of Business \\ Texas Christian University \\ d.preston@tcu.edu
}

\begin{abstract}
The use of information technologies (IT) in a supply chain has been recognized as essential for both organizational exploration and exploitation activities. Drawing upon organizational theories, we submit that a punctuated equilibrium approach is most viable in the context of supplier IT use for generating buyer benefits in a supply chain network. Through the analysis of matched-pair data collected from a major North American electronic components distributor and its key suppliers, we find that
\end{abstract}

\section{Introduction}

The use of information technologies (IT) has been essential to align SC partners' decisions, resources, and activities through facilitating knowledge sharing between them $[6 ; 30]$. Specifically, the use of IT has been recognized as a key characteristic of both the SC exploitation and exploration activities (13;16;21;30]. An example of SC exploitation can be described as the use of IT to automate cross-organizational tasks (e.g., billing, inventory management, report generating, etc.) with the goal of gaining increases in efficiency. In addition, IT can also be engaged in SC exploration purposes such as gathering business intelligence information to identify opportunities for innovation including new trends in sales or customer preferences [13]. An overall conclusion drawn from extant the IT and SCM literature reflects the view that an ambidextrous strategy that employs a dual and synchronous emphasis on both exploration and exploitation [2;25], leads to superior SC performance [16]. However, given the generally incompatible natures of the two activities, maintaining a balance or precise mix of exploration and exploitation at a specific time invariably creates a problem for organizations in practice [9;19]. As such, an alternative theoretical perspective is warranted to examine how to implement an

\section{Conceptual Development and Research Hypotheses}

\subsection{Balancing Exploitation and Exploration: Ambidexterity or Punctuated Equilibrium?}

the supplier's IT exploitation has direct influence on IT exploration, which in turn directly contributes to the buyer's operational and strategic benefits (and fully mediates the effect of IT exploitation). This study enriches both the IS and supply chain management literature by providing empirical findings that uncover the mechanisms through which collaborative supply chain IT use would influence value creation for trading partners.

ambidexterious strategy, particularly with regard to IT exploitation and exploration within a supply chain context. Second, although the value proposition for IT use in SC suggests reciprocal effects (i.e., the use of SC IT by one player should create value for its trading partners) [14], findings from extant studies largely reflect a one-sided view on value creation (i.e., buyers' or suppliers') benefits generated from their own use of IT [7;21;30]. As an effort to bridge the above research gaps, we draw on a punctuated equilibrium perspective, which emphasizes the existence of temporal cycling between the periods of exploitation and exploration [3;11;19] to propose a staged value creation model explaining how suppliers may achieve a long term balance between IT exploration and IT exploitation in order to deliver value to buyers. To test our research model, we sent questionnaires to both sides of a buyer-supplier relationship. Specifically, matched pair data were collected from 38 account executives of a major North American electronic components distributor and liaison managers from its 166 key suppliers to assess the dynamic relationship between the supplier's IT use leading to benefits provided to the buyer. 
There are two primary schools of thought related to the mechanisms exist to facilitate organizations to realize the balance between exploitation and exploration: 1) ambidexterity [2;13;19;22], and 2) punctuated equilibrium [3;23]. Scholars who promote the ambidexterity perspective contend that both exploitation and exploration should be pursued simultaneously. For example, Benner and Tushman [2] suggest that ambidexterity can be achieved through appropriate organizational design (e.g., highly differentiated but weakly integrated units). In contrast, the proponents of the punctuated equilibrium perspective emphasize temporal or cycling periods of exploitation and exploration, rather than simultaneity through organizational differentiation. A key assumption behind the tenets of punctuated equilibrium is the organization's need for simplicity (i.e., sequential allocation of attention

\subsection{IT Use for Exploitation and Exploration in Supply Chain Management}

The extant SCM literature acknowledges the necessity for organizations to pursue both exploitation and exploration for SC success and also widely recognizes that IT is instrumental for both SC exploitative and SC exploratory activities [16;21;30]. However, the current literature base often assumes ambidexterity is derived without considering the possibility of temporal cycling. Although we concur that from a strategic point of view, supply chain IT exploitation and exploration should and could co-exist. However, we propose from a tactical point view that the punctuated equilibrium approach is potentially more viable for suppliers to implement such an ambidexterious strategy.

First, the inter-organizational environment is often much more complex than an intra-organizational context. Many organizations strive for an IT-enabled SCM system in order to leverage IT for exploitation and exploration [4;30]. Therefore, in the context of our study, SCM is recognized as an entire system and a single domain, or a system-level architecture. According to the contingency perspective proposed by Gupta et al. [11], "long-term adaptation at the level of architecture requires sequential attention to exploitation and exploration - that is, punctuated equilibrium (p.698)". Second, the extant IT management literature suggests that there are divergent views by those on the business side of the organization regarding the roles and value of IT [9]. Third, maintaining an appropriate balance between exploitation and exploration is consistently a difficult task since organizational learning is often constrained by myopic viewpoints within the organization [19]. Due to the substantial investment in technologies and the high risk to divergent goals) due to frequent goal conflicts and bounded rationality [19]. Gupta et al. [11] offered a useful conceptual lens to understand the difference between the above two mechanisms in terms of orthogonality versus continuity. That is, the ambidexterity school views "exploitation” and "exploration” as orthogonal aspects of organizational behavior, whereas the punctuated equilibrium school considers them two extremes of a continuum. The literature has largely remained silent on how to achieve the balance of the two mechanisms can influence supply chain performance. We view the punctuated equilibrium perspective [11] is most suitable to examine the role of IT use to balance the exploitative and exploratory activities in a single domain (i.e., supply chain management), particularly when IT is recognized as a driving force for supply chain success from the supplier's perspective.

associated with the choice of a new dominant design, the returns from exploration are generally far less certain and more distant in time compared to the returns from exploitation [34]. In other words, as compared to exploitative activities, the engagement in explorative activities are usually hindered by a myopic adaptive process within the organization [23]. As such, due to the organizational inertia and myopia, it takes consideration effort for companies to shift from one learning activity to the other within a domain [18].

Establishing a SC IT program requires investing a portfolio of supply chain technologies, which can be generally be categorized in terms of operational support systems (OSS) versus interpretation support systems (ISS) [13]. Given the varying natures of the two (i.e., OSS for exploitation, ISS for exploration), the problems associated with myopia are not new to the supply chain IT investment decision making process. The IT management literature has suggested that, due to the costs and uncertainty accompanied with IT investment, many business executives primarily seek to gain short-term efficiency-based performance indicators to assess the effectiveness of IT functions [4]. Considering the managerial myopia as well as the nature that exploitation allows current viability and exploration grants future, Chen et al. [4] proposed a staged maturity model showing that organizational exploitative use of IT drives exploratory use of IT. Based upon the above discussion, we suggest the balance of IT use for supply chain exploitation and exploration will not likely to be achieved simultaneously. Rather, suppliers will first focus on investing and using IT for exploitative supply chain 
activities (e.g., to automate and integrate various transactions with the buyers). Once business executives have derived short-run performance gains (e.g., operational excellence, customer relationship improvement, revenue growth) from an integrated supply chain IT platform [28], they are likely to seek exploratory knowledge sharing opportunities with their supply chain partners that will bring long-term rewards [13]. As such, organizations will move towards more exploratory use of IT in their supply chain practices. We therefore posit:

\section{H1: The supplier's use of IT for exploitation} positively influences its use of IT for exploration.

\subsection{Supplier IT Use for Buyer Value Creation}

Although IT has been widely regarded as a critical value creation driver at the entire SC level, surprisingly the are scant empirical studies that provide direction on how exactly an organization's pattern of IT use can create value for trading partners ${ }^{1}$. Patterns of IT use reflect organizational intention, purpose, or motivation. We follow the collaborative view (i.e., the strategic intent of SC IT use is for inter-firm collaboration) [29] to examine how suppliers' patterns of IT use can benefit buyers. In accordance with prior SC IT use literature [21;30], we assess two types first-order buyer benefits. Operational benefits result from transactional and production costs savings. Strategic benefits arise through new business opportunities identified via exchange relationships. We offer a fine-tuned interpretation to submit that the two patterns of supplier IT use create values to buyers along different paths: suppliers' IT use for exploration has direct impacts to buyers' strategic and operational benefits, whereas the effect from IT exploitation is indirect via IT exploration.

From the supplier's perspective, although SC technologies create asset specificity risks, the use of these technologies have also brought proven benefits to them [21;30]. IT not only allows suppliers to align decisions, resources, and activities with buyers, but also help them timely respond to challenges of changing customer requirements and environmental turbulence. For example, the use of IT greatly improves suppliers information sharing and production planning with buyers, which results in significant cost savings to the suppliers through automated invoicing and inventory tracking. Meanwhile, the use of IT also enhances joint innovation planning between the suppliers and buyers for new products and

1 An exception is Im and Rai [13] who investigates how coordinate IT use between trading partners improve relational outcomes as assessed by both sides. However, the
It is important to note that our theorizing should not be interpreted as a one-way route via the IT exploitation and exploration path. Rather, it reflects a starting point towards long term success. In fact, the punctuated equilibrium perspective reflects a dynamic view on temporal iterations between alternatives in order to secure attention to both of them over time [32]. Organizational IT program decisions generally involve prioritization, sequencing and many other types of controlling activities. As such, $H 1$ should be regarded a strategic choice as well as a starting position towards ultimate excel in achieving exploitation/exploration balance.

programs, thus bringing strategic benefits to the suppliers. From the buyers' perspective, when suppliers are motivated, engaged and locked in through routinely elated IT-enabled exploitation and exploration with them, they have a higher potential to capture value from its products and services [29]. As such, both IT exploitation and IT exploration activities of suppliers help with generating efficiency and novelty values to buying firms [13].

However, the nature of the two patterns of IT use are different, suggesting supplier IT exploitation and exploration may create value to buyers along varying routes. Engaging in exploitation involves activities focusing on operational coordination and production efficiency; while engaging in exploration means the emphasis lies on experimentations and tests [22;30]. As such, the technologies involved for the two types of activities may be quite different. Typically, operational support systems are used for SC exploitation. These systems help with integrating inter-firm operations that coordinate partner's actions thereby enabling partnering firms to better understand each other's information needs to efficiently execute SC processes. Furthermore, SC IT exploitation also provide visibility to existing routines and errors thereby enabling firms to refine or improve existing processes [13;20]. With the advancement of business intelligence and analytics technologies, interpretation support systems [13] have become increasingly popular for SC exploration activities. These sense making systems improve firms capacity: to scan the environment; analyze existing and new information; identify trends and opportunities; and offer novel cognitive frameworks to revolutionize products/services offerings.

performance measures they used were primarily operational performance, no strategic benefits were investigated. 
Compared to exploitation, exploration typically demands more organizational resources and incurs greater risk of failure. However, the impact of exploration diffuses beyond the organization boundary [30]. The future and external oriented explorative uses of IT are the source of supply chain innovation thereby representing greater growth opportunities for supply chain partners [29;30]. Im and Rai [13] argue that the use of IT for SC exploration facilitates the synergistic pursuit of alignment and adaptation between partners. In particular, advanced business intelligence systems support processing massive amounts of data and multiple views of information interpretation, which enhance partners' mutual understanding about the trends, patterns and types of change they face. These sensemaking capabilities could greatly expand the capacities of trading partners to both refine existing routines of operational activities as well as seek novel ways for customer offerings. Thus, we state formally:

H2: The supplier's use of IT for exploration positively influences the buyer's (a) operational benefits and (b) strategic benefits.

Whereas the supplier IT exploration has an overarching impact on buyer value creation, we reason the

\section{Research Methodology}

\subsection{Questionnaire Administration and Data Collection}

To conduct this research study which focuses on the buyer-supplier relationship we selected a single buyer and its relationship with its multitude of suppliers. Specifically, the buyer was represented by a sole company based in the States that is a distributor of electronic components (i.e. the "Distributor"). This Distributor has its corporate/operational headquarters located in the United States, with a total of 269 electronics components suppliers when at the time this study was conducted. Preliminary interviews were initially conducted with the executive leadership of the Distributor to explore the nature of the relationship between this organization as a buyer and its suppliers. We wish to emphasize that the Distributor represents an appropriate buyer within the buyer-supplier organizational relationship. The Distributor at the center of this study does not merely act a "middle-man" between its suppliers and ultimate end user, rather, it focuses on product development and redesign for the ultimate use for the final customer.

We utilized a survey instrument to collect data from both the suppliers' and the Distributor's personnel through questionnaires to test the research hypotheses. In impact of supplier IT exploitation to buyers may not be a direct impact but rather more likely and indirect impact through exploration. First, SC exploitation activities generally have a more localized impact and internal focus than exploration [30]. Second, suppliers are typically more sensitive to collaboration failure than buyers. They are disproportionally smaller in size and must appropriate larger portion of their budgets to develop SC technological capabilities. Since exploitation and exploration demand investments in profoundly different technological and human assets, most suppliers will prioritize IT use for exploitation ahead of exploration. In other words, suppliers tend to reap immediate local efficiency before considering further investments to expand its exploration capacities which have a long-term direct impacts to buyers. This reasoning is consistent with the argument of learning myopia [19]. Third, IT management literature provides the support that exploitative IT practices typically contribute to strategic value through explorative [4]. As such, we propose:

H3: The supplier's use of IT for exploration mediates the influences of its use of IT for exploitation to the buyer's (a) operational and (b) strategic benefits.

this study we targeted each of the Distributor's 269 suppliers. For the respondent on the supplier side, we sought the supplier's manager who was directly in charge of the buying-supplying relationship with the Distributor. These supplier managers were verified by the Distributor's senior executive management. The suppliers served as key respondents for questions associated with supplier IT exploitation and supplier IT exploration while the Distributor personnel served as respondents for questions associated with operational and strategic benefits derived by the buyer. With the goal of obtaining responses from both sides of the buyer-supplier dyad, we employed a dual-stage matched sampling strategy to administer the surveys. The first stage of this sampling strategy was conducted in October 2011, in which three rounds of an electronic survey was sent to each of the 269 supplier liaison managers (contact information was provided by the Distributor). We obtained a response rate of $61.7 \%$ yielding a total of 166 returned surveys from the suppliers. The survey electronically tracked the identity of the supplier respondent, which allowed the researchers to assess that there were no apparent issues any issues of 
response bias in the supplier sample pool (i.e., through the comparison of firm characteristics for responding and non-responding firms via ANOVA). In the second stage of the survey administration process (completed in December 2011), we sent a questionnaire to executive/managerial personnel at the Distributor (directly involved with each respective supplier) to assess

\subsection{Measures}

All constructs used for this study were measured via multi-item scales. The survey questionnaire contains several existing valid instruments that were adapted to for the context of the current research study. The survey questionnaire was developed and validated through a three-step process. First, semi-structured interviews were held with the Distributor's executive management team to: evaluate content validity of the initial construct items; better understand the ongoing phenomenon in greater detail; and refine the instrument accordingly. Second, using the refined instrument, we used the services of a number of appropriate academics and industry managers/executives to conduct an item sorting exercise to qualitatively evaluate the discriminant validity of each of the measured constructs [24]. Lastly, the psychometric

\section{Data Analysis and Results}

To establish the nomological validity of the research model, we used partial least square (PLS), a latent structural equations modeling technique that utilizes a component-based approach to do the estimation. The psychometric properties of all scales were assessed within the context of the measurement model through assessment of discriminant validity and reliability. Table 1 provides a summary of the descriptive statistics of the variables used in the study. All variables in our research model are modeled as reflective constructs. The psychometric properties of the scales are assessed in terms of item loadings, internal consistency, and discriminant validity. Item loadings and internal consistencies greater than 0.70 are generally considered acceptable [8]. The results of the

After examining the measurement validity, we employed PLS to test the structural model. The significance of the paths was determined using the Tstatistic calculated with the bootstrapping technique. As we have discussed, we include a series of control variables for each of the dependent variables in the research model (supplier size, buyer-supplier relationship length in time, supplier level of dependency on the buyer, and environmental uncertainty experienced in the supplier's marketplace). The results show that supplier dependency on the Distributor influences both the buyer's operational the Distributor's operational and strategic benefits derived from the buyer-supplier relationship. We obtained multiple responses from Distributor personnel for each of the responding 166 suppliers, for which a high level interrater agreement (via $r_{w g}$ ) was derived [15], thus an average response value was used

properties of the scales were statistically assessed. As we have noted, the supplier liaison manager was the key respondent for the following variables: supplier IT exploitation and supplier IT exploration while the Distributor personnel were the key respondents for buyer operational and strategic benefits. The items and scales used to measure these constructs are included in Appendix A. Based on our review of prior literature, we also included a series of control variables for each of the dependent variables in our research model: the size of the supplier (number of employees), the length of time of the buyer-supplier relationship (years), supplier's level of dependency on the buyer, and environmental uncertainty experienced in the supplier's marketplace (Appendix A).

factor analysis (Table 2) and composite reliability scores (Table 3) reveal that all scales used in the study meet these guidelines. We also observed discriminant validity as set forth by Chin [5]: (i) indicators load more strongly on their corresponding construct than on other constructs in the model (Table 2); and (ii) the square root of the average variance extracted are larger than the inter-construct correlations (Table 3).

\section{Table 1. Summary Statistics \\ Table 2. Results of factor analysis \\ Table 3. Inter-construct correlations}

and strategic benefits. It was essential to control for this dependency as the literature has established that inequities in the buyer-supplier relationship can influence performance outcomes derived by both the buyer and supplier [10;33]. None of the other control paths for any of the control variables were observed to be significant. The path coefficients and explained variances in the dependent variables for the structural model are shown in Figure 2. Table 4 presents a summary of the hypothesis results, which shows that all hypothesized causal paths in the research model were significant. We conducted 
mediation analyses to further assess the nomological network of the research model [1;31]. Following the approach outlined by Baron and Kenny [1], we first removed the IT exploration variable from the model and established direct links from IT exploitation to both buyer operational and strategic benefits, which indicate that IT exploitation has a significant direct effect on both buyer operational and strategic benefits. Next, using our original model (in Figure 2), we added direct links from IT exploitation to both buyer operational and strategic benefits (with the IT exploration variable retained in the model), which indicates that that neither direct path from

\section{Discussion of Findings, Implications, and Future Research}

As hypothesized, we observe that supplier IT exploitation is a significant predictor of supplier IT exploration. This finding supports the proposition that IT use between the buyer and supplier is a sequential process in which the exploitative use of IT in routine functions is needed for the more in-depth exploratory use of IT in business operations and strategic development. We observe that this finding is consistent with the findings from empirically tested studies. Furthermore, we observe that supplier IT exploration fully mediates the influence of supplier IT exploitation on both operational and strategic benefits derived by the buyer from this organizational relationship with suppliers. The literature has noted the need to examine the nature through which these IT components work in an integrated sequential fashion to influence performance. In the current study, following the spirit of the punctuated equilibrium perspective, we are able to provide empirical support to initially fill this gap. Unlike prior studies which examine IT use in as independent antecedents, we provide additional insight by proposing and demonstrating a sequential pathway through which supplier IT use can influence to organizational benefits for the buyer. In particular, we have identified and empirically confirmed two types of buyer benefits, namely operational and strategic benefits, which are direct outcomes of the IT exploration. These findings advance the tenets of the punctuated equilibrium perspective theory as applied to the domain of supply chain management.

Before we further discuss the theoretical and practical contributions, we acknowledge some limitations of the study. First, even though the causal relationships depicted in our hypotheses were all grounded in theory, the research methodology employed a cross-sectional design and as such does not allow for the establishment of the full causality between the independent variables and the dependent variables in the research model. Future
IT exploitation to either dimension of buyer benefits was statistically significant with the IT exploration variable retained in the model, thus supporting full mediation. Sobel's [31] tests provide support that IT exploration mediates the effect of IT exploitation on both buyer operational benefits $(\mathrm{t}=2.18, \mathrm{p}<0.05)$ and buyer strategic benefits $(\mathrm{t}=2.90, \mathrm{p}<0.01)$, thus supporting Hypothesis 3.

Figure 2. PLS Results

Table 4. Summary of Hypothesis Results research should look to employ a longitudinal study to potentially address this issue. In particular, a longitudinal study may be able to provide additional insight into the relationships examined in our model. Second, we note that the study was designed to provide a high level of respondent validity for each of the variables in the model while also designed to mitigate concerns with common method variance (CMV); however, it was necessary for the supplier to be the key respondent for both IT exploitation and exploration. We determine that CMV is not likely to be a source of bias in this relationship for a series of reasons: a) the supplier liaison manager was the appropriate respondent for both variables, b) Harman's single-factor test revealed no indication of CMV; and c) the inclusion of the marker variable provided additional support that CMV is not a concern between these two variables [12;27]. Third, non-response bias could possibly be present even though the response rate for the study was appreciable (61.7\%). However, no significant differences were found between responding and non-responding organizations based on firm characteristics and also there were various levels of IT use and SC performance observed from the respondents in our sample. Finally, the single industry sampling frame is not fully generalizable. However, we note that the electronics industry is an appropriate population for this study and we suggest future research seek to examine other industries.

As a response to the calls for further theory-driven research to how technology is employed to derive performance benefits in the context of supply-chain management, the current study offers several theoretical contributions. We highlight these theoretical development opportunities emerging from our research findings below. We examine the "black box" that exists with regard to the sequential process in how the suppliers' use of IT influences buyer benefits. As such, this study delivers a large-scale field survey approach to test an integrated 
theoretical model that examines such a phenomenon. In this study, we focused on how the routine exploitative use of IT is a predecessor of IT exploration, which is a more in-depth integration of IT in organizational practices. Future research should seek to further understand how IT usage between the buyer and supplier may have reciprocal effects. In addition, we also extend the level of understanding of the nature of the IT exploitationexploration relationship in that IT exploration is a key mediating factor to delivering buyer benefits. Future research should look to examine this phenomenon further with greater granularity. Furthermore, in the current study, we examine buyer benefits in term of operational and strategic benefits, which is consistent with the extant supply chain management literature. Future research should seek potentially to extend the benefits derived from IT use to other relevant organizational outcomes such as service quality, operational flexibility, and market growth.

In terms of managerial practice, our study provides several implications that emerge for both the supplier and the buyer. First, we emphasize the critical role of both IT exploitation and IT exploration. In particular, we address the process through which the supplier can work to provide benefits to the buyer through the collaborative use of technology. As such, this study outlines actionable methods through which the buyer can seek to gain performance benefits through technology partnerships. Suppliers and buyers seek to develop and utilize IT in an exploitative and explorative way to selectively yield organizational benefits in an iterative fashion. In addition, management should provide an organizational environment which facilitates IT use. The facilitation of IT exploration is particularly important since this deeper level of technology integration is most central to driving organizational benefits. In conclusion, this study enriches the both the IS and supply chain management literature by providing empirical findings that uncover the mechanisms through collaborative IT use between trading partners would influence organizational performance of the buyer. As such, this study provides a framework for future research to build on to further examine how buyersupplier use of technology can create organizational value.

\section{References}

[1] Baron, R. M., and Kenny, D. A. 1986. "The Moderator-Mediator Variable Distinction in Social Psychological Research: Conceptual, Strategic, and Statistical Concerns," Journal of Personality and Social Psychology (51), pp. 1173-1182.

[2] Benner, M. J., and Tushman, M., L. 2003. "Exploitation, Exploration, and Process Management: The Productivity Dilemma Revisited," Academy of Management Review (28:2), pp 238-256.

[3] Burgelman, R. A. 2002. "Strategy as Vector and the Inertia of Coevolutionary Lock-in," Administrative Science Quarterly (47:2)

[4] Chen, D. Q., Preston, D. S., and Xia, W. 2010. "Antecedents and Impacts of CIO Supply-side and Demand-side Leadership: A Staged Maturity Model," Journal of Management Information Systems (27:1) Summer, pp 231-271.

[5] Chin, W. W. (1998). The partial least squares approach to structural equation modeling. Modern methods for business research. G. A. Marcoulides. Mahwah, NJ, Erlbaum: 295-336.

[6] Dyer, J. H., \& Hatch, N. W. (2006). Relation-specific capabilities and barriers to knowledge transfers: Creating advantage through network relationships. Strategic Management Journal, 27(8), 701-719.

[7] Fawcett, S. E., Wallin, C., Allred, C., Fawcett, A. M., and Magnan, G. M. 2011. "Information Technology as an Enabler of Supply Chain Collaboration: A Dynamic-Capabilities Perspective," Journal of Supply Chain Management (47:1) January, pp 38-59.

[8] Fornell, C., and Larcker, D. F. 1981. "Evaluating Structural Equations Models with Unobservable Variables and Measurement Error," Journal of Marketing Research (18:1), pp. 39-50.

[9] Gregory, R. W., Keil, M., Muntermann, J., and Mähring, M. 2015. "Paradoxes and the Nature of Ambidexterity in IT Transformation Programs," Information Systems Research (26:1) March, pp 57-80.

[10] Griffith, D. A., Hoppner, J. J., Lee, H. S., and Schoenherr, T. 2017. "The Influence of the Structure of Interdependence on the Response to Inequity in Buyer-Supplier Relationships," Journal of Marketing Research (54: 1) February, pp 124-137.

[11] Gupta, A. K., Smith, K. G., and Shalley, C. E. 2006. "The Interplay Between Exploration and Exploitation," Academy of Management Journal (49:4), pp 693-706.

[12] Harman, H. H. (1967). Modern Factor Analysis. Chicago, University of Chicago Press.

[13] Im, G., and Rai, A. 2008. "Knowledge Sharing Ambidexterity in Long-Term Interorganizational Relationships," Management Science (54:7) July, pp 1281-1296.

[14] Im, G., and Rai, A. 2014. "IT-Enabled Coordination for Ambidextrous Interorganizational Relationships," Information Systems Research (25:1) March, pp 72-92.

[15] James, L. R., Demaree, R. G., and Wolf, G. (1984). "Estimating within-group interrater reliability with and without response bias”. Journal of Applied Psychology, 69(1), 85-98.

[16] Kristal, M. M., Huang, X., and Roth, A. V. 2010. "The effect of an ambidextrous supply chain strategy on combinative competitive capabilities and business performance," Journal of Operations Management (28:5) September, pp 415-429

[17] Krause, D. R., Handfield, R. B., and Tyler, B. B. 2007. "The relationships between supplier development, commitment, social capital accumulation and performance improvement”. Journal of Operations Management, 25(2), pp. 528-545.

[18] Lavie, D., and Rosenkopf, L. 2006. "Balancing exploration and exploitation in alliance formation," Academy of Management Journal (49:4), pp 797-818. 
[19] Levinthal, D. A., and March, J. G. 1993. "The Myopia of Learning," Strategic Management Journal (14), pp 95-112.

[20] Malhotra, A., Gosain, S., and El Sawy, O. A. 2005. "Absorptive Capacity Configurations in Supply Chains: Gearing for Partner-Enabled Market Knowledge Creation " MIS Quarterly (29:1) March, pp 145-187

[21] Mani, S. 2004. "How Do Suppliers Benefit from Information Technology Use in Supply Chain Relationships," MIS Quarterly (28:1) March, pp 45-73.

[22] March, J. G. 1991. "Exploration and Exploitation in Organizational Learning," Organization Science (2:1), pp 71-87.

[23] March, J. G. 2006. "Rationality, foolishness, and adaptive intelligence," Strategic Management Journal (27:3) March, pp 201-214.

[24] Moore, G. C.,and Benbasat, I. (1991). "Development of an instrument to measure the perceptions of adopting an information technology innovation. Information Systems Research”, 2(3), pp. 192-223.

[25] O'Reilly, C. A., and Tushman, M. L. 2004. "The Ambidextrous Organization," Harvard Business Review (82:4) April, pp 74-81.

[26] Pavlou, P. A., \& El Sawy, O. A. (2006). From it leveraging competence to competitive advantage in turbulent environments: The case of new product development. Information Systems Research, 17(3), 198-227.

[27] Podsakoff, P. M., Scott, B. M., Lee, J.-Y., and Podsakoff, N. P. 2003. "Common method biases in behavioral research: A critical review of the literature and recommended remedies”. Journal of Applied Psychology, 88, 879-903.

[28] Rai, A., Patnayakuni, R., and Patnayakuni, N. 2006. "Firm performance impacts of digitally enabled supply chain integration capabilities," MIS Quarterly (29:4), pp 625-652.

[29] Rai, A., and Tang, X. 2014. "Research Commentary_Information Technology-Enabled Business Models: A Conceptual Framework and a Coevolution Perspective for Future Research," Information Systems Research (25:1) March, pp 1-14.

[30] Sanders, N. R. 2008. "Pattern of information technology use: The impact on buyer-suppler coordination and performance " Journal of Operations Management (26:3) May, pp 349-367

[31] Sobel, M. E. 1982. "Asymptotic Confidence Intervals for Indirect Effects in Structural Equation Models," in Social Methodology, S. Leinhardt (ed.). San Francisco: Jossey-Bass, pp. 290-312.

[32] Smith, W. K., and Lewis, M. W. 2011. "Toward a Theory of Paradox: A Dynamic equilibrium Model of Organizing," Academy of Management Review (36:2) April, pp 381-403.

[33] Villena, V. o. H., and Craighead, C. W. 2017. "On the Same Page? How Asymmetric Buyer-Supplier Relationships Affect Opportunism and Performance," Production \& Operations Management (26:3) March, pp 491-508.

[34] Zhou, K. Z., and Wu, F. S. 2010. "Technological capability, strategic flexibility, and product innovation " Strategic Management Journal (31:5) May, pp 547-561

\section{Appendix A. Construct Operational Definitions and Scales}

Supplier IT Exploitation: IT Exploitation is defined as the degree to which the supplier uses IT with the buyer to develop levels of efficiency and consistency and improve current methods. Source: [30]; Interviews; Scale: Not at All (1) - To a Very Great Extent (5). Please indicate the extent to which your firm and "The Distributor" Allied use Information Technology to communicate with each other for the following: IT Exploit1: Order processing, invoicing and settling accounts; IT Exploit2: Exchange of shipment and delivery information; IT Exploit3: Managing warehouse stock and inventories

Supplier IT Exploration: IT Exploration is defined as the degree to which the supplier uses IT with the buyer to experiment and discover new innovate methods. Source: [30]; Interviews; Scale: Not at All (1) - To a Very Great Extent (5). Please indicate the extent to which your firm and "The Distributor" Allied use Information Technology to communicate with each other for the following: IT Explore1: Understanding trends in sales and customer preferences; IT Explore1: Integrating your design and manufacturing functions; IT Explore3: Leveraging your firm's expertise to create new business opportunities (e.g., lead sharing, product expertise, etc.)

Buyer Operational Benefits: Buyer Operational Benefits are defined as the extent to which the Distributor is receiving operational benefits as a result of its relationship with each supplier. Source: [30]. Scale: No Benefit (1) - Very High Benefit

(5). Over the last year, to what extent has your firm received the following benefits as a result of your relationship with "The Distributor”? OpBen1: Cost efficiencies from higher sales volumes; OpBen2: Improvements to current processes or creation of new processes; OpBen3-Profit: Improved profitability

Buyer Strategic Benefits: Buyer Strategic Benefits are defined as the extent to which the Distributor is receiving strategic benefits as a result of its relationship with each supplier. Source: [30]; Scale: No Benefit (1) - Very High Benefit (5). Over the last year, to what extent has your firm received the following benefits as a result of your relationship with "The Distributor"? StratBen1: Learning about customers and markets for new products; StratBen2: Creation of new products, product enhancements; StratBen3: Development of new business opportunities 
Control Variables: 1. Supplier Size Number of Employees [17];

2. Relationship Length: How long has your firm had a business relationship with “The Distributor”? (years)

3. Supplier's Dependency on the Distributor: The Supplier's Dependency on the Distributor is defined as the degree to which the supplier's business operations depend on the existing relationship with the Distributor. Source: [17] Scale: Strongly Disagree (1) - Strongly Agree (7). Please assess the relationship of your firm with the Distributor:

SupDep1: If "The Distributor" stopped working with us, we could readily sell the same volume of product(s) through another distributor(s) (reverse coded); SupDep2: It would be relatively easy for our company to find another distributor(s) for the product(s) that we provide to "The Distributor" (reverse coded); SupDep3: If the relationship between our company and "The Distributor" was terminated, it would hurt our operations.

4. Environmental Uncertainty: Environmental Uncertainty is defined as the degree to which the supplier's market generates unpredictable demands for its services. Source; [26] Scale: Strongly Disagree (1) - Strongly Agree (7). Please assess the nature of your firm's external environment. EnvUn1: Our clients regularly ask for new products and services; EnvUn2: In our market, the volumes of products and services to be delivered change fast and often.

\section{TABLES}

Table 1. Summary Statistics

\begin{tabular}{|c|c|c|c|c|c|}
\hline Variable & $\mathbf{N}$ & Mean & Std Dev & Min. & Max \\
\hline 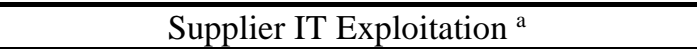 & 164 & 3.33 & 1.03 & 1.00 & 5.00 \\
\hline Supplier IT Exploration $^{a}$ & 163 & 2.83 & 1.04 & 1.00 & 5.00 \\
\hline Buyer Operational Benefits ${ }^{b}$ & 166 & 4.27 & 0.94 & 1.00 & 7.00 \\
\hline Buyer Strategic Benefits ${ }^{b}$ & 166 & 4.32 & 1.00 & 1.00 & 7.00 \\
\hline Supplier Size (Number of Employees) & 152 & 3,227 & 11,299 & 10 & 100,000 \\
\hline Supplier-Distributor Relationship Length (years) & 152 & 15.77 & 10.98 & .50 & 80.00 \\
\hline Supplier’s Dependency on the Distributor ${ }^{\mathrm{b}}$ & 165 & 4.24 & 1.21 & 1.00 & 7.00 \\
\hline Environmental Uncertainty ${ }^{\mathrm{b}}$ & 166 & 4.31 & 1.11 & 1.50 & 7.00 \\
\hline
\end{tabular}

a 5-point scale ranging from "not at all” (1) to "to a very great extent" (5)

b 7-point scale ranging from "strongly disagree (1) to strongly agree (7)

Table 2. Results of Factor Analysis

\begin{tabular}{|c|c|c|c|c|}
\hline & IT Exploit & IT Explore & Op Ben & Strat Ben \\
\hline IT Exploit1 & $\mathbf{0 . 8 8 1}$ & 0.546 & 0.159 & 0.249 \\
IT Exploit2 & $\mathbf{0 . 9 1 1}$ & 0.594 & 0.220 & 0.277 \\
IT Exploit3 & $\mathbf{0 . 8 6 8}$ & 0.688 & 0.242 & 0.266 \\
\hline IT Explore1 & 0.616 & $\mathbf{0 . 9 2 2}$ & 0.251 & 0.341 \\
IT Explore2 & 0.642 & $\mathbf{0 . 8 8 1}$ & 0.195 & 0.235 \\
IT Explore3 & 0.624 & $\mathbf{0 . 9 0 3}$ & 0.276 & 0.347 \\
\hline OpBen1 & 0.180 & 0.209 & $\mathbf{0 . 8 2 7}$ & 0.541 \\
OpBen2 & 0.246 & 0.234 & $\mathbf{0 . 9 2 7}$ & 0.882 \\
OpBen3 & 0.208 & 0.279 & $\mathbf{0 . 9 4 4}$ & 0.798 \\
\hline StratBen1 & 0.270 & 0.307 & 0.823 & $\mathbf{0 . 9 6 4}$ \\
StratBen2 & 0.294 & 0.333 & 0.834 & $\mathbf{0 . 9 6 4}$ \\
StraBen3 & 0.293 & 0.346 & 0.737 & $\mathbf{0 . 9 4 3}$ \\
\hline
\end{tabular}

Table 3. Inter-construct Correlations

\begin{tabular}{|c|c|c|c|c|c|}
\hline & Reliability ${ }^{\text {a }}$ \# items) & IT Exploit & IT Explore & Op Ben & Strat Ben \\
\hline IT Exploit & $0.917(3)$ & 0.887 & & & \\
\hline IT Explore & $0.929(3)$ & 0.694 & 0.902 & & \\
\hline OpBen & $0.928(3)$ & 0.237 & 0.268 & 0.901 & \\
\hline StratBen & $0.970(3)$ & 0.298 & 0.343 & 0.835 & 0.957 \\
\hline
\end{tabular}

Notes: ${ }^{\text {a }}$ Composite Reliability. The shaded numbers on the leading diagonal are the square root of the AVE 
Table 4. Summary of Hypothesis Results

\begin{tabular}{|c|c|}
\hline Hypotheses & Result \\
\hline H1: Supplier IT Exploitation $\rightarrow$ Supplier IT Exploration & Supported** \\
\hline H2a: Supplier IT Exploration $\rightarrow$ Buyer Operational Benefits & Supported** \\
\hline H2b: Supplier IT Exploration $\rightarrow$ Buyer Strategic Benefits & Supported** \\
\hline H3: Supplier IT Exploration Mediates: $:$ IT Exploitation $\rightarrow$ Buyer Benefits & Supported $\wedge$ \\
\hline
\end{tabular}

Note: * Significant at $0.05 ;{ }^{* *}$ Significant at $0.01 ; \wedge$ supported by Sobel Tests

\section{FIGURES}

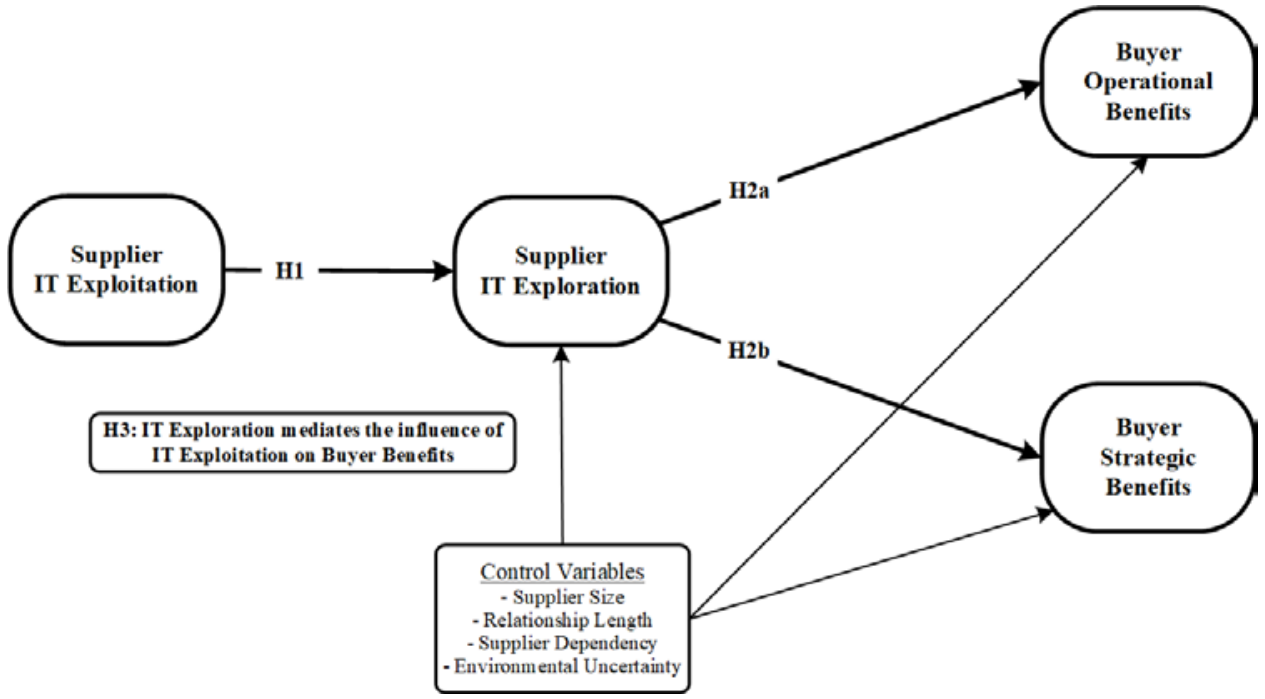

Figure 1. Research Model

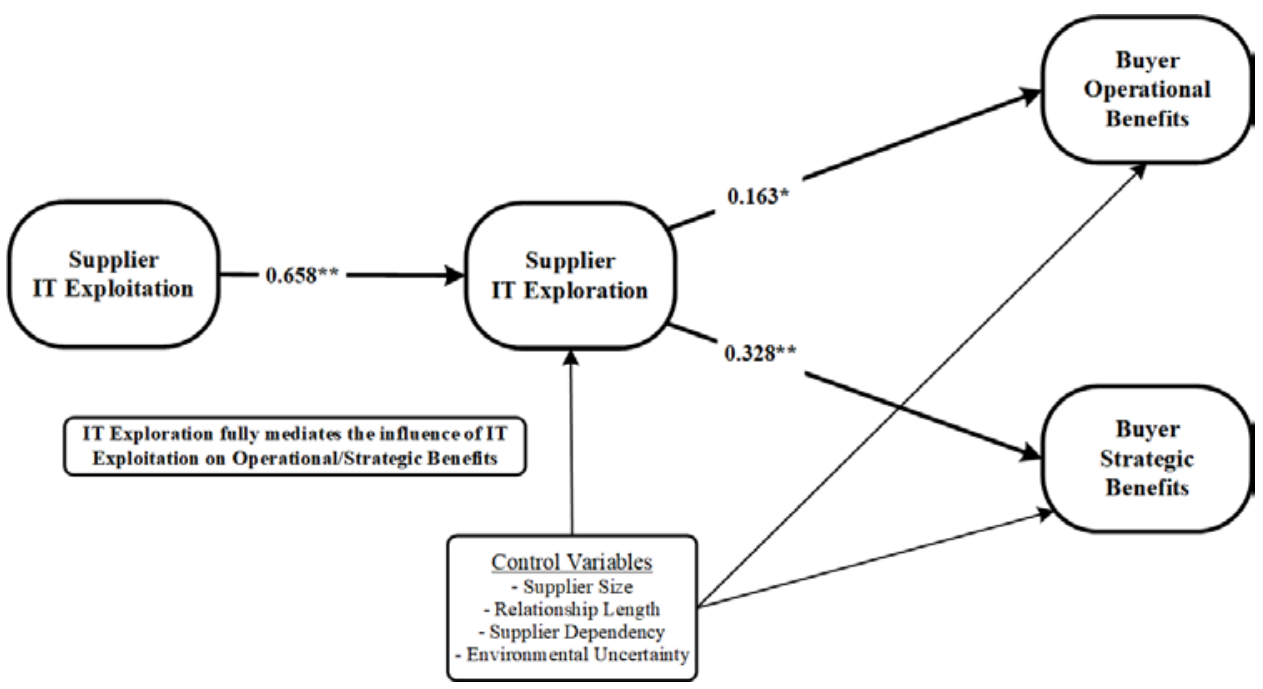

Figure 2. PLS Results

Note: ** Significant at $0.01 ; *$ Significant at 0.05

1 Buyer-Supplier IT Exploitation was observed to explain 48.2\% of the variance in Buyer-Supplier IT Exploration beyond that explained by the control variables. Buyer-Supplier IT Exploration was observed to explain $7.3 \%$ and $11.9 \%$, respectively, of the variance in Buyer Operational Benefits and Buyer Strategic Benefits that explained by the control variables. 